\title{
Mere presence of informal guardians deters burglars: a virtual reality study
}

\author{
Iris van Sintemaartensdijk ${ }^{1,2}$. Jean-Louis van Gelder ${ }^{3,4}$. \\ Jan-Willem van Prooijen ${ }^{1,5} \cdot$ Claire Nee $^{6} \cdot$ Marco Otte $^{7} \cdot$ Paul van Lange ${ }^{1}$
}

Published online: 14 April 2020

(C) The Author(s) 2020

\begin{abstract}
Objectives This study investigates the deterrent effects of incremental levels of guardianship on residential burglary and assesses how burglars differ from non-burglars in terms of their perceptions of opportunities for burglary.

Methods In a virtual reality experiment, 181 incarcerated burglars and 172 nonburglars (university students) were tasked to appraise a virtual neighbourhood in search of a burglary target. During the appraisal process, participants were exposed to different levels of guardianship, ranging from the mere presence of a guardian to an intervening guardian.
\end{abstract}

Results The presence of a guardian deterred both burglars and non-burglars alike, with only negligible incremental effects for levels of guardianship. For burglars, guardianship increased the perceived likelihood of being caught and the perceived level of social cohesion, whereas it decreased neighbourhood attractiveness. The burglars differed from the non-burglars in terms of how they appraised the virtual neighbourhood, clearly reflecting differences in expertise between both groups.

Conclusions With respect to residential burglary, the results suggest that guardians - in line with the original notion of guardianship developed by Cohen and Felson (American Sociological Review, 44(4), 588-608, 1979) — serve as a deterrent simply by being present.

Keywords Burglary · Deterrence · Expertise - Guardianship · Virtual reality

Burglary ranks among the most feared crimes reported in crime surveys, due to not only its prevalence (Ceccato 2016) but also its impact on feelings of safety (Ruijsbroek et al. 2015). One factor that has consistently been found to reduce burglary is the presence of residents in and around their homes (Bennett and Wright 1992; Coupe and Blake 2006;

Iris van Sintemaartensdijk

i.van.sintemaartensdijk@vu.nl

Extended author information available on the last page of the article 
Cromwell et al. 1991; Wright et al. 1995). The presence of one or more individuals who can, intentionally or unintentionally, act to deter a (potential) criminal event is commonly referred to as 'guardianship' (Hollis-Peel et al. 2011).

In spite of robust empirical evidence regarding the effectiveness of guardianship on crime prevention, significant gaps exist in scientists' understanding of what type of behaviour underlies the presence-deterrence nexus and, more specifically, what level of guardianship is required to generate a deterrent effect (Reynald 2009). Do guardians need to actively monitor their environment or is their mere presence sufficient to prevent a criminal event from taking place? Furthermore, most studies conducted thus far have been of a correlational rather than experimental nature (Coupe 2017; Kearns and Fincham 2005; van Bavel and Elffers 2013). In addition, previous research that has linked guardianship to burglary rates has not included the offender's perspective. However, addressing this perspective is important, as burglars have been shown to differ significantly from non-burglars in key aspects of the burglary process (e.g. Nee and Meenaghan 2006; Nee et al. 2015, 2019).

In the present study, we capitalise on the potential of virtual reality (VR) to provide an experimental test of the deterrent effects of different levels of guardianship among a sample of incarcerated burglars and a comparison group of non-burglars. Specifically, we aim to (a) investigate what level of guardianship is required to deter residential burglary and (b) examine how burglars differ from non-burglars in terms of their perceptions of opportunities for burglary.

\section{The effect of guardianship on burglars}

The term guardianship was first coined by Cohen and Felson (1979). According to their routine activity theory (RAT), crime is likely to take place when a motivated offender and a suitable target converge in time and place in the absence of a capable guardian. Whereas formal guardians (e.g. police officers, security guards) have a professional role in preventing crime, informal guardians are those who do not act out of a professional capacity (Elffers and Ruiter 2016). In line with RAT, empirical evidence suggests that increasing the number of available guardians decreases burglary rates. For example, unemployment has been linked to reduced burglary victimisation (D'Alessio et al. 2012), presumably because unemployed individuals spend more time at home, thereby increasing the number of guardians in a neighbourhood. In contrast, increased employment of women outside their homes, and hence reduced home occupancy, has been linked to increases in burglary rates (Bennett 1991).

In their original notion of the concept, Cohen and Felson (1979) envisioned guardianship as the mere presence (versus absence) of individuals. Mere presence was argued to provide unintentional supervision to a specific place and time through routine activities. Subsequent conceptualisations have extended the scope of guardianship to also include guardianship exhibited by objects, such as security cameras or alarms (e.g. Cohen et al. 1981), and the actual actions or behaviour of guardians (e.g. Reynald 2009). In the present study, we are particularly interested in the latter.

Reynald (2009) defined three successive levels of guardianship. The first level entails the mere presence of (a) guardian(s). The second level focuses on guardians actively monitoring their surroundings. In the third and highest level, guardians actively monitor 
their environment and ultimately intervene when they observe a potential offender. Preliminary evidence indicates that levels of guardianship are negatively correlated with property crimes (Reynald 2009). However, recent research suggests only minor increases in effectiveness between successive levels of guardianship (Moir et al. 2017). That being said, it is important to note that previous studies examining levels of guardianship were largely observational and correlational in nature, hence leaving open questions regarding causality (Reynald et al. 2018). In addition, whereas interview studies report higher numbers of monitoring and intervening guardians (Moir et al. 2018; Reynald 2010), monitoring and intervening guardians are less frequently observed in observational studies compared with mere present guardians and are therefore underrepresented in this research (Hollis-Peel and Welsh 2014; Hollis et al. 2019).

\section{The burglar's perspective on guardianship}

While early pioneering studies interviewed burglars on the deterrent effects of guardianship (e.g. Bennett and Wright 1992; Wright et al. 1995), more recent research has shifted focus and related crime levels to the observation of guardianship behaviour, thus leaving the offender's perspective out of the equation (Moir et al. 2017; Reynald 2009). However, we argue that including the offender's perspective is critical due to the unique expertise of offenders that impact their decision-making processes (Nee 2015).

Burglars have been found to accumulate unique expertise over time. This expertise results in a superior recognition and quicker assessment of burglary-related cues (Nee and Ward 2015; Coupe 2017). For example, burglars more quickly detect and pay attention to cues signalling wealth, occupancy, and security (Nee and Meenaghan 2006; Nee and Taylor 2000). Hence, it stands to reason that burglars will also be more attuned to cues of guardianship when compared with non-burglars.

Research has thus far not addressed how burglars appraise different levels of guardianship. Using experimental research designs, such an appraisal could be directly observed by recording the behaviour exhibited by the burglars in response to these varying levels. Additionally, by contrasting the responses of burglars to those of a nonoffender group, it is possible to place these findings in context and also highlight how expertise affects the assessment of guardianship.

\section{VR as a means to study guardianship}

Analogous to researching other types of offending, studying burglars in action has proven challenging both for practical and ethical reasons (van Gelder et al. 2014). The advent of VR technology, however, offers novel possibilities through its ability to simulate criminogenic contexts in a realistic way (e.g. van Gelder et al. 2017). Importantly, VR allows for a relatively faithful simulation of the real world (Mania and Chalmers 2001), while maintaining high levels of experimental control. That is, simulations can be kept identical for participants across experimental conditions with the exception of pre-established variations, to isolate the effects of the variables of interest (Blascovich et al. 2002). Furthermore, VR provides an opportunity to directly 
observe behaviour as it occurs, rather than after the events have transpired, as is the case with alternative methodologies commonly used to study offender behaviour, such as interviews and surveys (van Gelder et al. 2014).

Recent work has tapped into the potential of simulated environments to study burglar decision-making. Nee et al. (2015) exposed burglars and non-burglars (i.e. university students) to both an actual house and a virtual replica of the same house on a laptop computer, finding that the behaviour of burglars differed from that of nonburglars, but did not differ significantly between the virtual house and the actual house. In another recent study, Nee et al. (2019) compared the behaviour of experienced incarcerated burglars with that of other offenders and non-offenders in a simulated environment. This study showed the superior expertise of burglars compared with the other groups which manifested in differences in their decision-making. Specifically, burglars scoped the neighbourhood more thoroughly yet more efficiently than the other groups, spent more time in the high-value areas within the house they burgled while traveling less distance there, and also targeted different goods than the comparison groups.

\section{The present study}

This study was part of a larger data collection of the Virtual Burglary Project (VBP). The VBP aims to test hypotheses about burglary expertise and decision-making using VR. The present study had two goals. The first goal was to establish the effect of guardianship levels on burglar-perceived deterrence. The second goal involved the comparison of experienced burglars with non-burglars (i.e. university undergraduates) in terms of their perceptions of opportunities for burglary. Participants were instructed to scout a virtual neighbourhood for opportunities to commit a burglary and to proceed in a similar fashion as they would in the real world. During this process, they were exposed to a virtual guardian displaying one of three different levels of guardianship (mere presence, monitoring guardian, and intervening guardian) or did not encounter a guardian (control condition). After the scouting experience, participants were presented a survey in which they were questioned about perceived deterrence and neighbourhood attractiveness. We tested the assumption that for both burglars and non-burglars, perceived deterrence would increase in parallel with increases in the level of guardianship. Furthermore, we theorised that burglars would respond differently in terms of perceived deterrence in line with their superior expertise and be quicker and more efficient in the scouting process than non-burglars.

\section{Method}

\section{Participants and design}

In total, 353 participants (181 burglars, 172 non-burglars) took part in this study. Inclusion criteria for both samples were being proficient in Dutch, being at least 18 years of age, and not suffering from epilepsy. Participants were randomly assigned to one of the following conditions: 'mere present guardian' $(N=46$ 
burglars; $N=42$ non-burglars); 'monitoring guardian' ( $N=45$ burglars; $N=46$ non-burglars); 'intervening guardian' ( $N=43$ burglars; $N=41$ non-burglars); or a control condition without a guardian ( $N=47$ burglars; $N=43$ non-burglars). The participants' mean age was $32.94(S D=9.16)$ for burglars and $22.94(S D=5.19)$ for non-burglars. Country of origin was the Netherlands for $43 \%$ of the burglars and $81 \%$ of the non-burglars. All participants were male, as the burglar sample was collected in male-only prisons.

\section{Materials}

\section{Virtual environment}

The virtual environment (VE) was developed with the Unity Pro engine (version 2017.3.1f1). Participants viewed the VE through a head-mounted display (HMD), the Oculus Rift DK, with a stereoscopic view. An HMD allows for viewing in all directions via accelerometers, thus resembling a natural viewing experience. In addition to the HMD, participants were also provided with headphones delivering immersive audio (e.g. sounds of birds and cars in the distance, as well as the participant's own footsteps). Participants navigated the VE using a game controller.

The VE was designed to resemble a typical middle-class neighbourhood and consisted of several street segments, public squares, front and back gardens, and alleys (see Fig. 1 in the Appendix). Participants could freely walk around and look through windows of houses to see their interior (see Fig. 2a-2b in the Appendix). The neighbourhood further contained parked cars and other common features, such as lampposts, garbage bins, trees, and street signs. Two virtual agents (one male, one female) were programmed to walk around the neighbourhood at a distance from participants. All participants started in the same location (see Fig. 1 in the Appendix) and were instructed to walk around the neighbourhood as if they were scouting it for a potential burglary.

\section{Guardianship manipulation}

The guardianship manipulation consisted of a single virtual agent, the guardian (see Fig. 3 in the Appendix), who appeared from the front door of his house when a participant came within a distance of $25 \mathrm{~m}$ (approximately 27 yards) of his house (see Fig. 4 in the Appendix for these trigger zones). In all three experimental conditions, the virtual agent was engaged in a phone conversation and remained in his front yard. In the mere presence condition, the guardian appeared fully engaged in the phone conversation, was clearly not paying attention to his surroundings, and did not remark or acknowledge the participant. In the monitoring guardian condition, the guardian displayed the same behaviour as in the mere presence condition but looked directly at the participant once the participant came within a range of $17 \mathrm{~m}$ (approximately 18 yards) from the virtual agent and followed the participant with his gaze as long as the participant remained within a radius of $17 \mathrm{~m}$ from the guardian. The intervening guardian condition was identical to the monitoring condition with the difference that he intervened once the participant reached a distance of $10 \mathrm{~m}$ (approximately 11 yards) from the guardian, at which point the guardian approached him by walking several steps in his direction and addressed 
him with the question: 'You seem to be looking for something, can I help you?' In the control condition, no guardian was present.

As participants could freely traverse the neighbourhood, walking patterns varied. In order to ensure that participants would encounter the guardian in the guardianship conditions, the guardian could appear from one of four potential houses dispersed around the neighbourhood (see Fig. 4 in the Appendix). At least one of these houses would always be passed regardless of the participant's chosen trajectory. Only one guardian was activated per experimental session, the other three guardians remained invisible.

\section{Questionnaires}

Perceived deterrence In order to measure perceived deterrence, participants responded to eight questions measured on a 5-point scale (strongly disagreestrongly agree): difficulty to burgle in the neighbourhood (1 item, 'This neighbourhood appears difficult to burgle'), neighbourhood attractiveness (1 item, 'This neighbourhood is attractive to burgle'), chances of getting caught ( 1 item, 'If you burgle in this neighbourhood, the chances of getting caught are small'), social cohesion ( 2 items, $\alpha=.83$, 'Neighbourhood residents know each other well', 'Neighbourhood residents look out for each other'), likelihood of residents to call the police ( 1 item, 'Neighbourhood residents will call the police when they see a burglary taking place'), likelihood of residents intervening (1 item, 'Neighbourhood residents will intervene when they see a burglary taking place'), willingness to burgle in the neighbourhood now ( 1 item, 'If this neighbourhood would have existed in real life, would you have committed a burglary at this moment?'), and willingness to burgle in the neighbourhood later ( 1 item, 'If this neighbourhood would have existed in real life, would you have committed a burglary at a later point in time?'). These items include both direct (e.g. chances of getting caught) and more indirect aspects of perceived deterrence (e.g. social cohesion) and represent cues burglars are likely to pay attention to when selecting a target (e.g. Bennett and Wright 1992; Cromwell et al. 1991; Wright et al. 1995).

To investigate the factor structure of perceived deterrence, an exploratory factor analysis was conducted. A Kaiser-Meyer-Olkin measure of sampling adequacy indicated adequate sampling at .71. A principal-axis factor extraction-conducted to determine the factor structure with orthogonal rotation-yielded two factors with Eigenvalues larger than 1 . The first factor (encompassing the following items: difficulty to burgle the neighbourhood, neighbourhood attractiveness, chances of getting caught, willingness to burgle now, willingness to burgle later) had an Eigenvalue of 2.64 and explained $32.97 \%$ of variance. Factor loadings ranged from .50 to .80 . The second factor (encompassing the following items: perceived social cohesion, resident willingness to call the police, resident willingness to intervene) had an Eigenvalue of 1.46 and explained $18.18 \%$ of variance. Factor loadings ranged from .50 to .75 . No crossloadings above .40 were observed.

Factor 1 ( 5 items; $M=2.99, S D=.70$ ) reflected the perception of the neighbourhood and was labelled 'neighbourhood assessment'. Factor 2 (3 items; $M=3.37, S D=.49$ ) reflected perception of residents' potential intervening behaviour and was labelled 'resident responses'. Analyses were performed both for the two aggregate factors as well as for the underlying individual items. 
Manipulation checks Two items examined whether participants had noticed the guardian: 'Did you see any virtual people in the neighbourhood?' (yes/no), and 'If you did see people, what were they doing?' The latter question encompassed the behaviour of the guardian as well as that of the two background virtual agents who were incorporated to prevent participants from inferring the goal of the study.

Gaming experience To establish whether reactions to and behaviour in the virtual neighbourhood were influenced by the participants' level of gaming experience, they were asked how many hours per week they played videogames with a controller (burglars: $M=2.05, S D=6.74$; non-burglars: $M=3.06, S D=1.21$ ) or a keyboard (burglars: $M=.17, S D=1.52$; non-burglars: $M=2.86, S D=.33$ ). Burglars were asked to indicate how many hours per week they played prior to incarceration.

Presence Presence in the VE was assessed using an adapted version of the 8-item short Spatial Presence Experience Scale using a 5-point scale (strongly disagreestrongly agree) $(M=3.09, S D=.61, \alpha=.75)$ (Hartmann et al. 2016). This scale reflects the degree to which participants felt present in the virtual world (e.g. 'I felt like I was actually there in the virtual neighbourhood'). The questionnaire was translated into Dutch, and the wording for each item was altered from '.... the area of the presentation' to '...the virtual neighbourhood' for reasons of clarity. One item from the original scale was excluded for potentially being too difficult for the burglar sample ('It was as though my true location had shifted into the environment of the presentation').

Cyber-sickness Any discomfort suffered by a participant due to the VR was assessed through an adapted version of the Simulator Sickness Questionnaire $(M=2.69$, $S D=.76$ ) (Kennedy et al. 1993). To reduce participant burden, five core aspects of discomfort (i.e. nausea, stomach ache, dizziness, lack of focus, blurry vision) were selected from the original 15-item questionnaire. Participants rated their discomfort on a 5-point scale (e.g. 'The virtual environment made me dizzy') (strongly disagree-strongly agree).

Burglary experience To assess burglary experience among the burglar sample, burglars were asked to estimate the number of burglaries they had committed in their lifetime $(M=62.46, S D=281.61)$, a question commonly included when burglary experience is assessed (Nee et al. 2019). Nine of the incarcerated participants were excluded for not having burglary experience.

Self-reported delinquency To exclude potential burglars from the non-offender sample, a 22-item self-reported delinquency scale (Svensson et al. 2013) was administered among the student sample (e.g. 'How often in the last 2 years have you stolen something or taken something from another person, such as money, a cell phone, or clothes'; $\alpha=.84$ ) on a 5-point scale (strongly disagree-strongly agree). No offenders were present in the non-burglar sample, and hence, none had to be excluded. 


\section{Procedure}

Burglars were recruited in four different male-only prisons ${ }^{1}$ in the Netherlands. Recruitment took place via information flyers, by directly approaching inmates during leisure time, and via word of mouth among inmates. The prisons provided no prior information about the study to potential participants. Additionally, information flyers were phrased in general terms mentioning the use of VR and asking for people with burglary experience. Before taking part, burglars were asked whether they knew about the nature of the study. In addition, they were asked not to disclose any information about the study to other inmates afterwards. The student sample was recruited at two universities in the Netherlands via their respective recruitment systems, information flyers, and directly approaching potential participants on campus.

The informed consent procedure highlighted the confidentiality of the data and emphasised that participants' names and other potentially identifying information would not be recorded. After providing their informed consent, participants answered questions regarding their prior burglary experience (burglar sample) or self-reported delinquency (student sample), their gaming experience, and their demographics. Subsequently, they were asked to enter the virtual neighbourhood and instructed to walk around the neighbourhood as if they were assessing it for a potential burglary. Nonburglars were instructed to imagine being a burglar and given the same assignment. No time limit was specified. Any possible questions were answered before the trial started. Participants could exit the neighbourhood via one of three exits. Once they had exited, the experimental part of the session was completed. After removing the HMD and headphones, participants were asked to fill out the survey including the perceived deterrence, presence, and cyber-sickness items. Subsequently, they received a full debriefing on the purpose of the study. Inmates were offered support in the event that the experience had raised issues for them that they wished to discuss.

\section{Results}

\section{Preliminary analyses}

We first checked for potential differences between conditions and the two experimental groups. No significant differences emerged for the levels of guardianship on presence $\left(F(3,348)=.82, p=.48, \eta^{2}=.007\right)$ and cyber-sickness $(F(3,348)=.61, p=.61$, $\left.\eta^{2}=.005\right)$, nor were there differences between burglars and non-burglars being present $\left(F(1,350)=2.29, p=.13, \eta^{2}=.007\right)$ or cyber-sickness $(F(3,350)=.24, p=.63$, $\left.\eta^{2}=.001\right)$. Gaming experience was higher for the control condition $(M=10.07, S D=$ $28.89)$ compared with a mere present guardian $(M=4.44, S D=7.67)$, monitoring guardian $(M=4.02, S D=7.21)$, and intervening guardian $(M=2.82, S D=5.97)$, $\left(F(3,339)=3.57, p=.01, \eta^{2}=.03\right)$. Burglars and non-burglars also differed significantly on gaming experience, with $M=7.75$ and $S D=21.84$ and $M=3.06$ and $S D=$ 5.49 respectively $\left(F(1,341)=7.46, p=.007, \eta^{2}=.02\right)$.

\footnotetext{
${ }^{1}$ As the large majority of burglars are male (Bennett and Wright 1992), the study was conducted among males only.
} 


\section{Main analyses}

We performed a general linear model with the following independent variables: guardianship level and expertise (burglars versus non-burglars). Presence, cyber-sickness, and gaming experience were added as covariates for all analyses as they could potentially affect perception of the neighbourhood as well as time spent and distance travelled in the VE. The plan of analysis was structured as follows. First, we compared the different levels of guardianship at the aggregated factor level, followed by a comparison on the individual item level. For each set of analyses, we first established the effect of the four experimental conditions on the dependent variables. Subsequently, we performed planned comparisons contrasting the control condition with the three experimental conditions together to establish whether the effect guardianship is best presented as a dichotomy or as a matter of successive levels. Lastly, we tested for differences between the three levels of guardianship. These analyses were performed separately for burglars and for non-burglars. In the second part of the analyses, we compared the responses of burglars to the dependent variables to those of the nonburglars.

\section{Burglars}

Factor level results No significant effects emerged for burglars on neighbourhood assessment, resident responses, distance travelled, or time spent in the neighbourhood ( $p>.15$ for all analyses), indicating no differences between the control conditions and the three levels of guardianship (see Table 1 in the Appendix for means and SDs). Furthermore, contrast analyses indicated no significant differences between the control condition and guardianship in general, or between the three levels of guardianship ( $p>.15$ for all analyses).

Individual item results On the item level, there was a significant effect for the four experimental conditions on neighbourhood attractiveness $(F(3,165)=2.80, p=.04$, $\left.\eta^{2}=.05\right)$, as well as a marginally significant effect on chances of getting caught $(F(3$, $165)=2.59, p=.06, \eta^{2}=.02$ ). No significant differences emerged for perceived difficulty to burgle the neighbourhood, likelihood of residents intervening, likelihood of residents calling the police, social cohesion, willingness to burgle now, willingness to burgle later, time spent in neighbourhood, and distance travelled $(p>.15$ for all analyses).

Contrasting the control condition with guardianship in general (all three experimental conditions combined), the effects of neighbourhood attractiveness $(F(1,159)=5.68$, $\left.p=.02, \eta^{2}=.03\right)$ and chances of getting caught $\left(F(1,159)=7.74, p=.006, \eta^{2}=.05\right)$ were significant, whereas the effect of perceived social cohesion was marginally significant $\left(F(1,159)=3.66, p=.06, \eta^{2}=.02\right)$. No significant differences emerged for the other variables ( $p>.15$ for all analyses).

Contrasting the three levels of guardianship did not yield any differences at the item level ( $p>.15$ for all analyses). In conjunction, these results reflect a deterrent effect of guardian presence, irrespective of level of guardianship and with no incremental effects of successive levels of guardianship. 


\section{Non-burglars}

Factor level results In the non-burglar sample, there was a significant effect for resident responses $\left(F(3,164)=2.69, p=.05, \eta^{2}=.05\right)$. Contrast analyses yielded a significant difference between the control condition and guardianship in general $(F(1,164)=7.99$, $\left.p=.005, \eta^{2}=.05\right)$, but no differences between the three levels of guardianship $(p>.15$ for all analyses). These findings show that the likelihood of residents intervening was higher when a guardian was present, irrespective of level of guardianship (see Table 1 in the Appendix for means and $S D \mathrm{~s}$ ). There were no significant effects for non-burglars on neighbourhood assessment, distance travelled, or time spent in the neighbourhood ( $p>.15$ for all analyses).

Individual item results At the item level, there were significant differences for perceived difficulty to burgle $\left(F(3,164)=3.59, p=.02, \eta^{2}=.06\right)$ and for perceived social cohesion $\left(F(3,164)=2.73, p=.05, \eta^{2}=.05\right)$. No significant effects emerged for any of the other variables $(p>.15$ for all analyses).

Contrasting the control condition with guardianship in general, significant effects emerged for perceived difficulty to burgle $\left(F(1,164)=10.68, p=.001, \eta^{2}=.06\right)$ and social cohesion $\left(F(1,164)=5.87, p=.02, \eta^{2}=.04\right)$. Marginally significant effects emerged for chances of getting caught $\left(F(1,164)=3.32, p=.07, \eta^{2}=.02\right)$ and willingness to burgle the neighbourhood at a later point in time $(F(1,164)=3.05$, $p=.08, \eta^{2}=.02$ ). These findings indicate that when a guardian is present, irrespective of the level of guardianship, ratings of perceived difficulty, social cohesion, and chances of getting caught increase, while willingness to burgle decreases. Contrasting the three levels of guardianship was not significant to any of the items $(p>.15)$, providing further evidence against differences in perceived deterrence due to levels of guardianship.

\section{Burglars vs. non-burglars}

Factor level results Comparing burglars versus non-burglars on the aggregated factors, a significant effect emerged for resident responses $(F(1,332)=29.50, p<.001$, $\left.\eta^{2}=.08\right)$. Burglars $(M=3.50, S D=.48)$ assessed the likelihood of residents responding as higher than non-burglars $(M=3.22, S D=.45)$. No differences were found for neighbourhood assessment $(p>.15)$.

Individual item data On the individual item data, significant differences for burglars versus non-burglars were found for perceived difficulty to burgle the neighbourhood $\left(F(1,332)=5.87, p=.02, \eta^{2}=.02\right)$, neighbourhood attractiveness $(F(1,332)=12.17$, $\left.p=.001, \eta^{2}=.04\right)$, likelihood of residents intervening $(F(1,332)=25.12, p<.001$, $\left.\eta^{2}=.07\right)$, perceived social cohesion $\left(F(1,332)=22.52, p<.001, \eta^{2}=.06\right)$, time spent in the neighbourhood $\left(F(1,332)=3.89, p=.05, \eta^{2}=.01\right)$, and travelled distance in the neighbourhood $\left(F(1,332)=10.54, p=.001, \eta^{2}=.03\right)$. The effect on chances of getting caught was marginally significant $\left(F(1,332)=3.42, p=.07, \eta^{2}=.01\right)$.

Burglars rated the neighbourhood lower than non-burglars on difficulty to burgle the neighbourhood, attractiveness, and chances of getting caught and higher than non- 
burglars on likelihood of neighbourhood intervening and social cohesion. Time spent in the neighbourhood in seconds was lower for burglars than that for non-burglars. The same was found for distance travelled. These results indicate that, as predicted, burglars respond differently to perceived deterrence cues than non-burglars and are more efficient in the scouting process, in line with their superior expertise.

\section{Discussion}

In its original formulation, guardianship was seen as a presence versus absence phenomenon, bypassing the possibility of differential effects between different levels of guardianship (Reynald 2009). Studies that have thus far attempted to take levels of guardianship into account have done so in a non-experimental fashion (van Bavel and Elffers 2013). The present study is the first to experimentally assess the effect of different levels of guardianship on burglar-perceived deterrence.

In line with expectations, when guardianship was encountered by burglars, perceived social cohesion and chances of getting caught increased, whereas perceived neighbourhood attractiveness decreased. No differences, however, emerged between the three levels of guardianship on these variables. These findings suggest that the mere presence of a guardian increases perceived deterrence and that the incremental deterrent effect of increasing guardianship levels is small for residential burglary. Differences between burglars and non-burglars were found for perceived difficulty to burgle, perceived attractiveness, chances of getting caught, likelihood of neighbourhood residents to intervene, social cohesion, time spent in the virtual neighbourhood, and distance travelled in it. There were no differences between burglars and non-burglars for the effect of level of guardianship.

\section{Further understanding the deterrent effect of guardianship}

Our findings align with the original notion of guardianship by Cohen and Felson (1979), in which guardians deter by virtue of simply being present, rather than the view of guardianship as a matter of degree. The minor differences between a present, a monitoring, and an intervening guardian correspond with findings from earlier correlational studies on level of guardianship (Hollis-Peel et al. 2012; Reynald 2009). However, it is important to note that the lack of clear difference between these groups could be affected by the ambiguous risk that a merely present guardian poses to a would-be burglar. The difference between the mere presence of a guardian and one that is monitoring is arguably subtle and a merely present guardian can also evolve into a monitoring or intervening guardian (Wright and Decker 1994). This ambiguity could render differences in perceived risk between levels of actual guardian behaviour comparatively small. Nonetheless, while even a sticker of a pair of watchful eyes can, in some situations, reduce norm violations or misconduct (e.g. Bateson et al. 2006; Nettle et al. 2012), intervening guardians pose a more imminent threat to burglars than monitoring guardians (van Bavel and Elffers 2013). Conceptually, these stages are thus notably distinct from one another. 
Exploring the manipulation of guardianship behaviour and what constitutes mere presence, monitoring, or intervening guardianship is a necessary step in exploring the small differences in stages of guardianship. In the current study, the mere present guardian was not actively monitoring the participant while standing outside the house; mere present guardians are also present guardians not able to monitor activity due to their physical surroundings (e.g. street view blocked by a fence) (Reynald 2009). Intervening guardianship can take many forms, such as calling the police, physically confronting the burglar, or being verbally abusive. Perhaps varying the range of guardianship behaviour within each stage would create more notable differences between the stages.

This study made use of only a single guardian rather than multiple ones. The fact that even this single guardian had a clear effect on burglars supports the idea that guardians are effective deterrents for burglars. Increasing the number of available and visible guardians in a neighbourhood, irrespective of their behaviour, could therefore be an effective preventive measure (Elffers and Ruiter 2016; Miró 2014). However, whether or not there is an additive deterrent effect of multiple guardians requires further examination.

When further exploring the effects of guardianship, more attention could be given to individual differences between burglars, as these could be meaningfully related to the deterrent effect of guardianship. Bennett and Wright (1992) identified three types of burglars, ranging from low to high when it comes to planning their crime (see also Nee and Meenaghan 2006; Wright and Decker 1994). In the short term, each type of burglar will likely be deterred by the presence of guardians. However, burglars who tend to engage in more extensive criminal planning could decide to return to complete the burglary once the threat of the guardian has diminished or disappeared. Understanding the connection between guardianship and individual differences in burglars might therefore provide a more complete picture of the deterrent effect of guardianship.

Although there were only notably small differences between levels of guardianship, this study requires replication in other contexts to be able to draw firmer conclusions. In addition to varying the number of guardians and style of guardianship behaviour, and physical attributes of the guardian, as well as the type (e.g. rural versus urban, low versus high income, organised versus disorganised) and size of the neighbourhood should be addressed in future studies.

The differences in results between burglars and non-burglars in this study highlight the role of criminal (i.e. burglar) expertise. Similar to the findings reported by Nee et al. (2019), burglars appeared to be able to process burglaryrelated cues significantly more efficiently than non-burglars as evidenced in a shorter time spent in the neighbourhood. Burglars did however travel less distance compared with non-burglars, contrary to findings by Nee et al. (2019). This discrepancy between the present findings and those reported by Nee et al. (2019) is likely due to the more extensive environment that was used in the present study, and indicates expertise as burglars appear to make their decisions more quickly. The clear differences between burglars and non-burglars concerning their overall perception of the neighbourhood, in particular regarding cues of behaviour of residents, once again confirms the role of (dysfunctional) expertise (Nee and Meenaghan 2006; Nee and Taylor 2000; Roth and Trecki 2016). 
Although the burglars and non-burglars did not differ concerning the deterrent effect of the various levels of guardianship, the speed of guardianship detection is unknown. It is possible that expertise can result in differences concerning how quickly burglars perceive risks posed by guardianship and how they act accordingly. Indeed, previous research has found superior detection of burglary-related cues by burglars (Garcia-Retamero and Dhami 2009; Nee and Taylor 2000; Nee et al. 2019). With VR, it is now possible to assess the speed of detection of guardianship-related cues by using eye-tracking technology, a feature that was unavailable for the current study. When designing a virtual environment in which eye-tracking is incorporated to assess guardianship-related cues, researchers do need to test the extent to which such cues are clearly visible and whether or not gaming experience has an influence on speed of detection. Nevertheless, this ability will no doubt assist in expanding our understanding of the deterrent effect of guardianship while simultaneously testing the superior automatic recognition of burglary-related cues at a behavioural level.

In closing, several limitations of the study must be mentioned. Although the virtual environment provides the closest approximation to observing burglars in action, the interpretation of 'virtual' offending behaviour does warrant caution. Navigating a computer-simulated environment with a game controller while being incarcerated is different from scouting an actual neighbourhood, and the risks involved in an actual real-world burglary are difficult, if not impossible, to mimic virtually. In spite of these differences, past research has revealed striking similarities between virtual and real burglaries at the subjective, behavioural, and even physiological level (Nee et al. 2015, 2019; van Gelder et al. 2017). When designing the present study, great care was taken to ensure that refresh rates and rendering rates were adequate and not obvious to participants. Moreover, no differences were observed between the behaviour of those with extensive gaming experience and those without.

Another possible limitation of the study concerns the fact that the burglar sample could be biased, given that the most successful burglars are likely out on the street and not in prison (Cromwell et al. 1991). However, the burglars in this study were mostly incarcerated for crimes other than burglary, as was the case in previous studies (Nee et al. 2015, 2019). Furthermore, reviews of research among both incarcerated offenders and offenders outside of prison indicate consistency in the decision-making process as well as behaviour in these groups (Copes and Hochstetler 2010).

This study involved an experimental test of the potential of VR to measure the deterrent effect of guardianship. To the best of our knowledge, it was the first study to use immersive virtual reality to study criminal decision-making among an actual offender sample. Participant responses show that the simulation was effective, leading the way to expanding the use of VR to study burglary and other types of offending. For example, future studies could enable participants to interact with virtual agents or to include multiple virtual agents (to study co-offending) (Yaremych and Persky 2019). Another potential avenue for future research in this context is to examine the speed of detection of crime- and guardianship-related cues by using eye-tracking technology, which can be integrated with VR and can assist in expanding our understanding of the deterrent effect of guardianship while simultaneously testing the superior automatic recognition of burglary-related cues at a behavioural level. 


\section{Conclusion}

The literature on guardianship goes back several decades, but it is only recently that levels of guardianship have been distinguished. The present research supports the overall conclusion that informal guardianship matters. Moreover, our findings suggest that the mere presence of guardians may often be quite effective when it comes to discouraging those inclined to burgle from actually doing so. These conclusions contribute to the scientific literature and are in line with the original views that underlie the concept of informal guardianship (Cohen and Felson 1979). What is especially new is the finding that the use of VR is a useful tool to provide experimental evidence in support of the notion that the mere presence of guardians is already quite effective as a deterrent to burglary. We look forward to harnessing the future research potential of VR (and perhaps other tools) to further understand the power of informal guardians to maintain and promote safety in communities.

\section{Compliance with ethical standards}

Conflict of interest The authors declare that they have no conflict of interest.

Ethical approval The studies have been approved by the ethical committee of the Faculty of Behavioural and Movement Sciences of the Vrije Universiteit Amsterdam national research ethics committee and have been performed in accordance with the ethical standards as laid down in the 1964 Declaration of Helsinki and its later amendments or comparable ethical standards.

\section{Appendix}

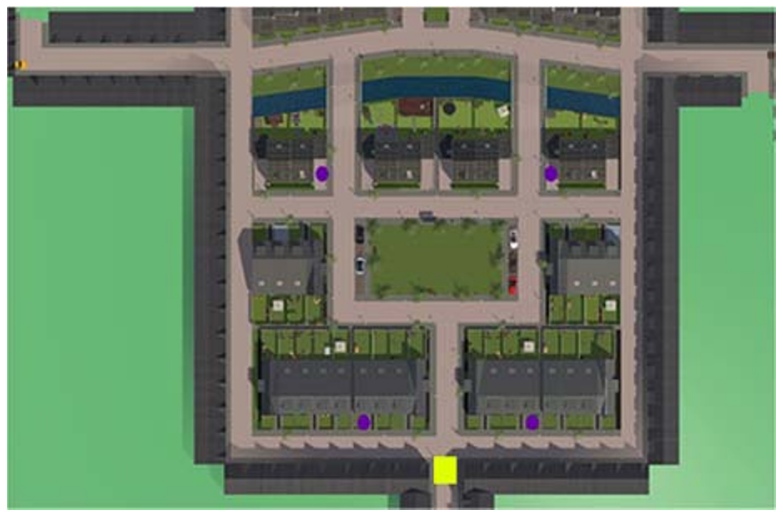

Fig. 1 Neighbourhood layout. The yellow square indicates the participant starting location; purple squares indicate the location where the guardian could appear 


\section{a}

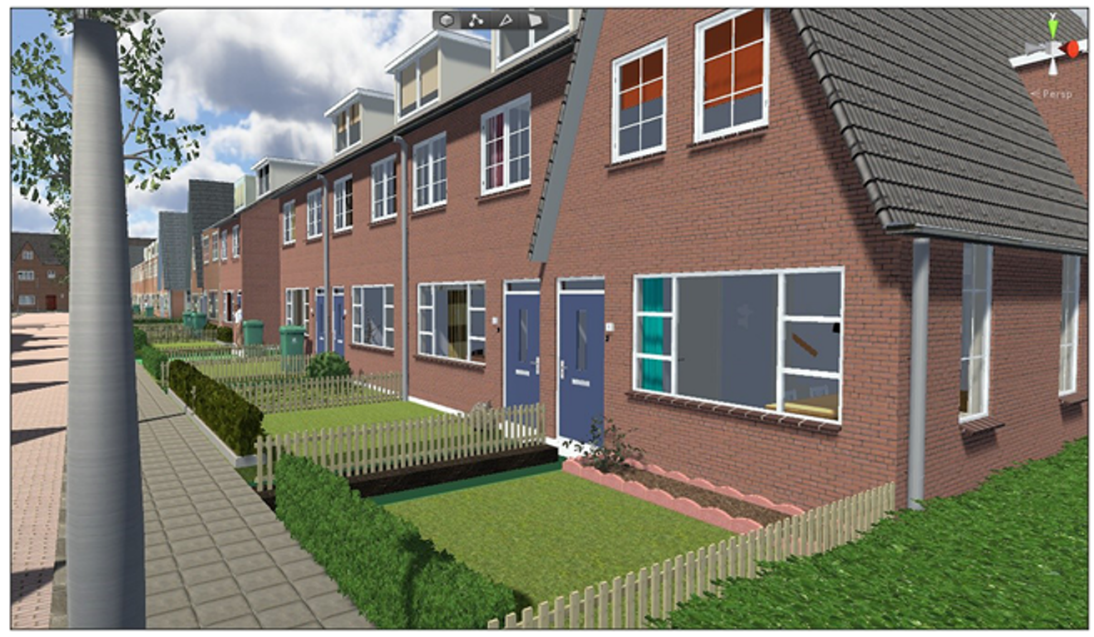

\section{b}

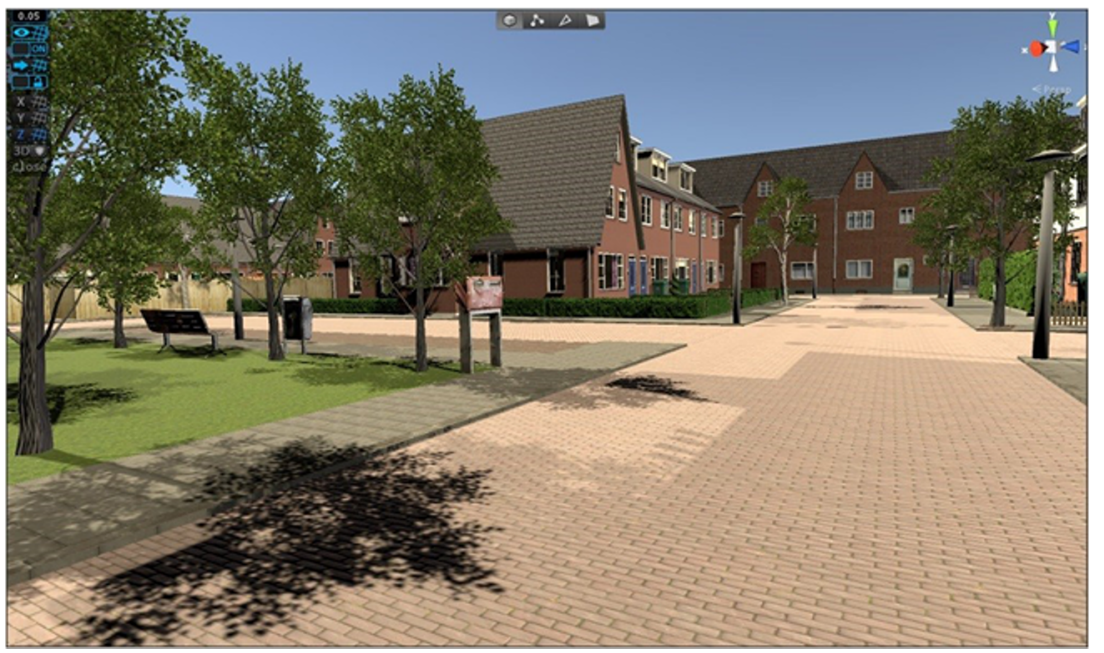

Fig. 2 a, b Impression of the virtual neighbourhood 


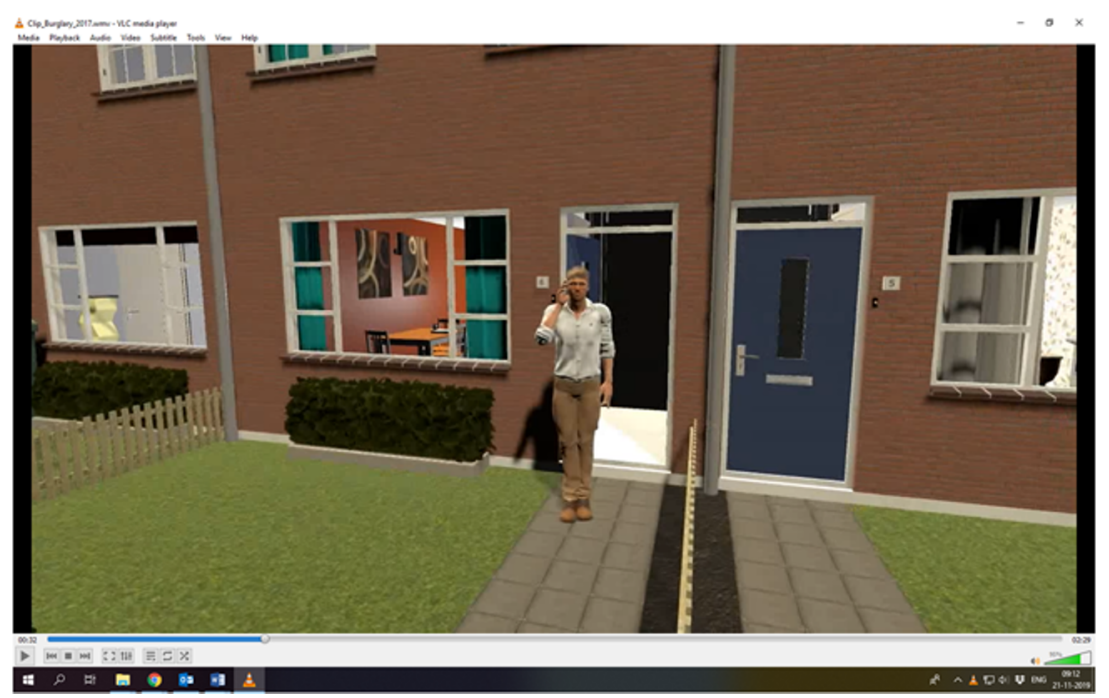

Fig. 3 Guardian in the virtual neighbourhood

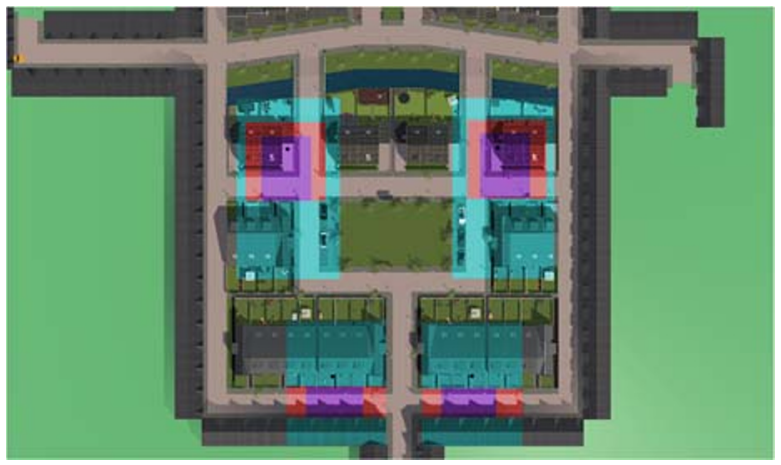

Fig. 4 Guardian trigger zones. Light blue square: trigger zone for guardian to appear from house; red square: trigger zone for monitoring guardian; purple zone: trigger for intervening guardian; black spot indicates guardian position

\section{亚 Springer}




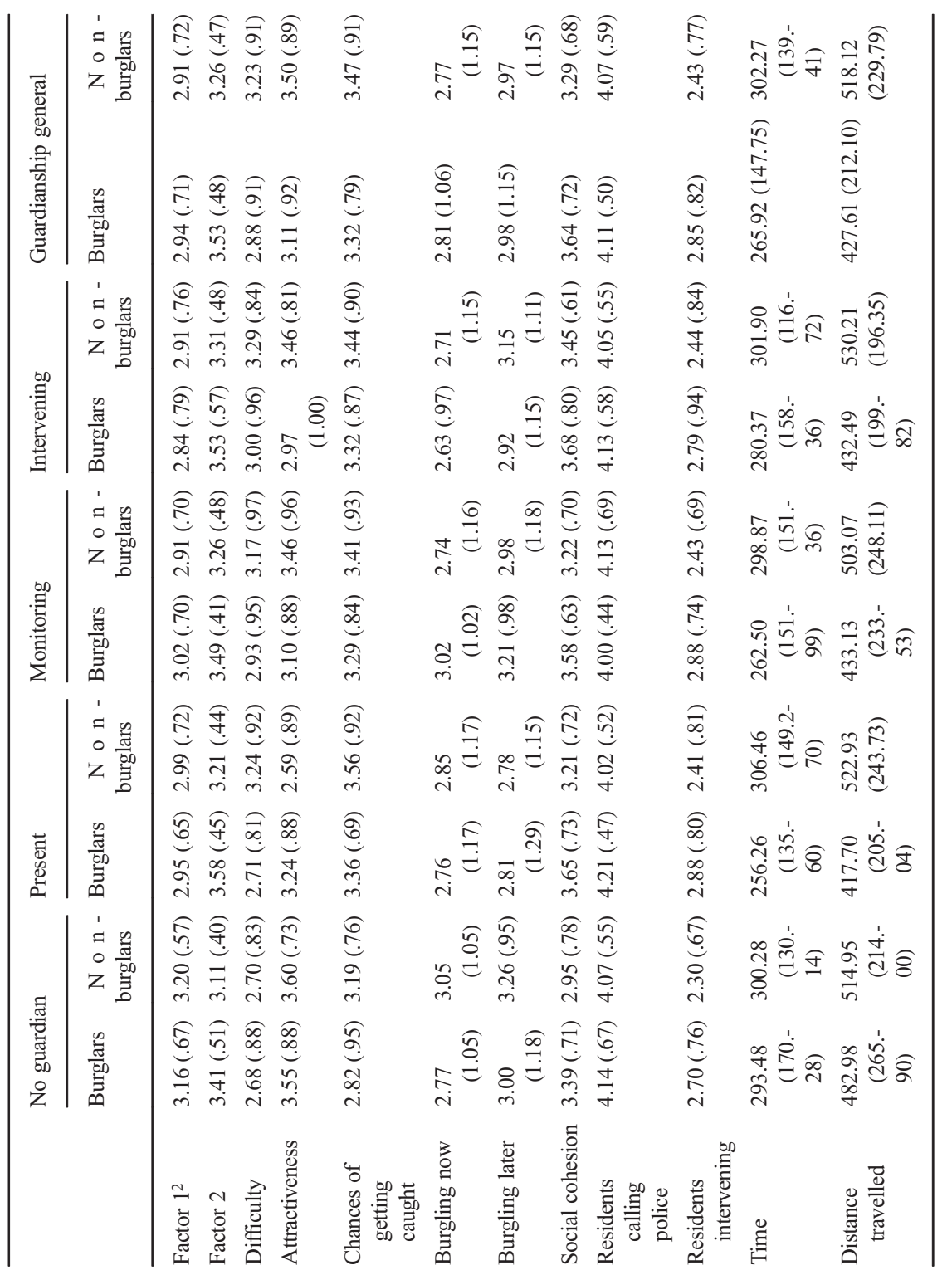
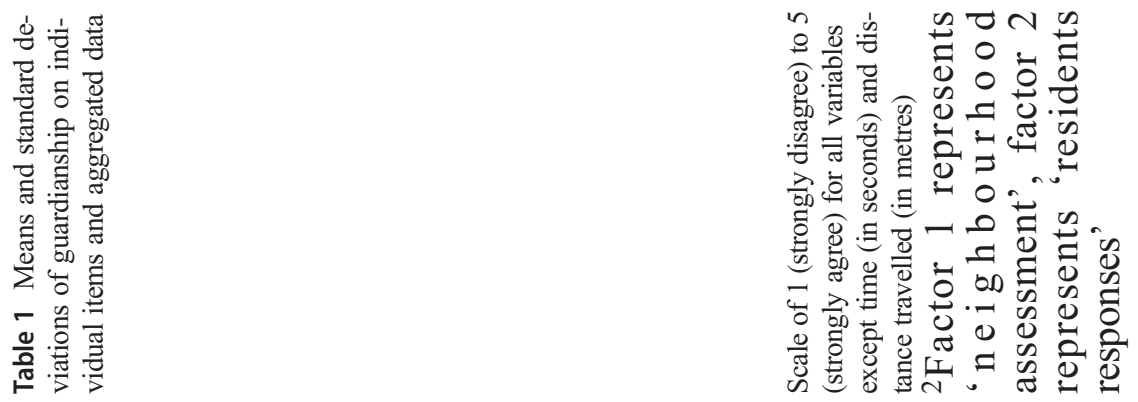
Open Access This article is licensed under a Creative Commons Attribution 4.0 International License, which permits use, sharing, adaptation, distribution and reproduction in any medium or format, as long as you give appropriate credit to the original author(s) and the source, provide a link to the Creative Commons licence, and indicate if changes were made. The images or other third party material in this article are included in the article's Creative Commons licence, unless indicated otherwise in a credit line to the material. If material is not included in the article's Creative Commons licence and your intended use is not permitted by statutory regulation or exceeds the permitted use, you will need to obtain permission directly from the copyright holder. To view a copy of this licence, visit http://creativecommons.org/licenses/by/4.0/.

\section{References}

Bateson, M., Nettle, D., \& Roberts, G. (2006). Cues of being watched enhance cooperation in a real-world setting. Biology Letters, 2(June), 412-414. https://doi.org/10.1098/rsbl.2006.0509.

Bennett, R. R. (1991). Routine activities : a cross-national assessment of a criminological perspective. Social Forces, 70(1), 147-163. https://doi.org/10.2307/2580066.

Bennett, T., \& Wright, R. (1992). Burglars on burglary: prevention and the offender. Aldershot: Gower.

Blascovich, J., Loomis, J. M., Beall, A. C., Swinth, K. R., Hoyt, C. L., Bailenson, N., \& Bailenson, J. N. (2002). Immersive virtual environment technology as a methodological tool for social psychology. Psychological Inquiry, 13(2), 103-124. https://doi.org/10.1207/S15327965PLI1302.

Ceccato, V. (2016). Rural crime and community safety. Abbington: Routledge.

Cohen, L. E., \& Felson, M. (1979). Social change and crime rate trends: a routine activity approach. American Sociological Review, 44(4), 588-608. https://doi.org/10.2307/2094589.

Cohen, L. E., Kleugel, J. R., \& Land, K. C. (1981). Social inequality and predatory criminal victimization: an exposition and test of a formal theory. American Psychologist, 46(5), 505-524. https://doi.org/10.2307 $/ 2094935$.

Copes, H., \& Hochstetler, A. (2010). Interviewing the incarcerated: pitfalls and promises. In W. Bernasco (Ed.), Offenders on offending: learning about crime from criminals (pp. 71-89). Devon: Willan Publishers.

Coupe, T. (2017). Burglary decisions. In W. Bernasco, J.-L. van Gelder, \& H. Elffers (Eds.), Oxford handbook on offender decision making (pp. 655-683). Oxford University Press.

Coupe, T., \& Blake, L. (2006). Daylight and darkness targeting strategies and the risks of being seen at residential burglaries. Criminology, 44(2), 431-463. https://doi.org/10.1111/j.1745-9125.2006.00054.x.

Cromwell, P. F., Olson, J. N., \& Wester Avary, D. (1991). Breaking and entering: an ethnographic analysis of burglary. Newbury Park: Sage.

D’Alessio, S. J., Eitle, D., \& Stolzenberg, L. (2012). Unemployment, guardianship, and weekday residential burglary. Justice Quarterly, 29(6), 919-932. https://doi.org/10.1080/07418825.2011.605073.

Elffers, H., \& Ruiter, S. (2016). Wie niet weg is, kan wat zien. In A. Dirkzwager, J.-L. van Gelder, \& S. Ruiter (Eds.), Beroemd en berucht: criminaliteit in Amsterdam (p. 136).

Garcia-Retamero, R., \& Dhami, M. K. (2009). Take-the-best in expert-novice decision strategies for residential burglary. Psychonomic Bulletin \& Review, 16(1), 163-169. https://doi.org/10.3758/pbr.16.1.163.

Hartmann, T., Wirth, W., Schramm, H., Klimmt, C., Vorderer, P., Gysbers, A., et al. (2016). The spatial presence experience scale (SPES): a short self-report measure for diverse media settings. Journal of Media Psychology, 28(1), 1-15. https://doi.org/10.1027/1864-1105/a000137.

Hollis, M. E., Fenimore, D. M., Caballero, M., \& Hankhouse, S. (2019). Examining guardianship in action in Waco, Texas. Crime Prevention and Community Safety, 21(1), 68-80. https://doi.org/10.1057/s41300-018-0056-5.

Hollis-Peel, M. E., \& Welsh, B. C. (2014). What makes a guardian capable? A test of guardianship in action. Security Journal, 27(3), 320-337. https://doi.org/10.1057/sj.2012.32.

Hollis-Peel, M. E., Reynald, D. M., van Bavel, M., Elffers, H., \& Welsh, B. C. (2011). Guardianship for crime prevention: a critical review of the literature. Crime, Law and Social Change, 56(1), 53-70. https://doi. org/10.1007/s10611-011-9309-2.

Hollis-Peel, M. E., Reynald, D. M., \& Welsh, B. C. (2012). Guardianship and crime: an international comparative study of guardianship in action. Crime, Law and Social Change, 58(1), 1-14. https://doi. org/10.1007/s10611-012-9366-1.

Kearns, J. N., \& Fincham, F. D. (2005). Victim and perpetrator accounts of interpersonal transgressions: selfserving or relationship-serving biases? Personality and Social Psychology Bulletin, 31(3), 321-333. https://doi.org/10.1177/0146167204271594. 
Kennedy, R. S., Lane, N. E., Berbaum, K. S., \& Lilienthal, M. G. (1993). Simulator sickness questionnaire: an enhanced method for quantifying simulator sickness. The International Journal of Aviation Psychology, 3, 203-220. https://doi.org/10.1207/s15327108ijap0303_3.

Mania, K., \& Chalmers, A. (2001). The effects of levels of immersion om memory and presence in virtual environments: a reality centered approach. Cyberpsychology \& Behavior, 4(2), 247-264. https://doi. org/10.1089/109493101300117938.

Miró, F. (2014). Routine activity theory. The Encyclopedia of Theoretical Criminology, 1979, 1-7. https://doi. org/10.1002/9781118517390.wbetc198.

Moir, E., Stewart, A., Reynald, D. M., \& Hart, T. C. (2017). Guardianship in action (GIA) within Brisbane suburbs. Criminal Justice Review, 42(3), 254-269. https://doi.org/10.1177/0734016817724199.

Moir, E., Hart, T. C., Reynald, D. M., \& Stewart, A. (2018). Typologies of suburban guardians: understanding the role of responsibility, opportunities, and routine activities in facilitating surveillance. Crime Prevention and Community Safety, 21(1), 1-21. https://doi.org/10.1057/s41300-018-0057-4.

Nee, C. (2015). Understanding expertise in burglars: from pre-conscious scanning to action and beyond. Aggression and Violent Behavior, 20, 53-61. https://doi.org/10.1360/zd-2013-43-6-1064.

Nee, C., \& Meenaghan, A. (2006). Expert decision making in burglars. British Journal of Criminology, 46(5), 935-949. https://doi.org/10.1093/bjc/azl013.

Nee, C., \& Taylor, M. (2000). Examining burglar's target selection. Psychology, Crime \& Law, 6(1), 1-31. https://doi.org/10.1109/eisic.2015.39.

Nee, C., \& Ward, T. (2015). Review of expertise and its general implications for correctional psychology and criminology. Aggression and Violent Behavior, 20, 1-9. https://doi.org/10.1016/j.avb.2014.12.002.

Nee, C., White, M., Woolford, K., Pascu, T., Barker, L., \& Wainwright, L. (2015). New methods for examining expertise in burglars in natural and simulated environments: preliminary findings. Psychology, Crime \& Law, 21(5), 507-513. https://doi.org/10.1080/1068316x.2014.989849.

Nee, C., van Gelder, J.-L., Otte, M., Vernham, Z., \& Meenaghan, A. (2019). Learning on the job: studying expertise in residential burlgars using virtual environments. Criminology, 39. https://doi.org/10.1111/1745-9125.12210.

Nettle, D., Nott, K., \& Bateson, M. (2012). 'Cycle Thieves, We Are Watching You’: impact of a smple signage intervention against bicycle theft. PLoS One, 7(12), 8-12. https://doi.org/10.1371/journal.pone.0051738.

Reynald, D. M. (2009). Guardianship in action: developing a new tool for measurement. Crime Prevention and Community Safety, 11(1), 1-20. https://doi.org/10.1057/cpcs.2008.19.

Reynald, D. M. (2010). Guardians on guardianship: factors affecting the willingness to supervise, the ability to detect potential offenders, and the willingness to intervene. Journal of Research in Crime and Delinquency, 47(3), 358-390. https://doi.org/10.1177/0022427810365904.

Reynald, D. M., Moir, E., Cook, A., \& Vakhitova, Z. (2018). Changing perspectives on guardianship against crime: an examination of the importance of micro-level factors. Crime Prevention and Community Safety, 20(4), 268-283. https://doi.org/10.1057/s41300-018-0049-4.

Roth, J. J., \& Trecki, V. L. (2016). Burglary expertise: comparing burglars to other offenders. Deviant Behavior, 38(2), 188-207. https://doi.org/10.1080/01639625.2016.1196972.

Ruijsbroek, A., Droomers, M., Groenewegen, P. P., Hardyns, W., \& Stronks, K. (2015). Social safety, selfrated general health and physical activity: changes in area crime, area safety feelings and the role of social cohesion. Health and Place, 31, 39-45. https://doi.org/10.1016/j.healthplace.2014.10.008.

Svensson, R., Weerman, F. M., Pauwels, L. J., Bruinsma, G. J., \& Bernasco, W. (2013). Moral emotions and offending: Do feelings of anticipated shame and guilt mediate the effect of socialization on offending? European Journal of Criminology, 10(1), 22-39. https://doi.org/10.1177/1477370812454393.

van Bavel, M., \& Elffers, H. (2013). Experiments in guardianship research. Experimental Criminology: Prospects for Advancing Science and Public Policy, 90-107. https://doi.org/10.3366 /edinburgh/9780748620227.003.0006.

van Gelder, J.-L., Otte, M., \& Luciano, E. C. (2014). Using virtual reality in criminological research. Crime Science, 3(1), 10. https://doi.org/10.1186/s40163-014-0010-5.

van Gelder, J. L., Nee, C., Otte, M., Demetriou, A., van Sintemaartensdijk, I., \& van Prooijen, J. W. (2017). Virtual burglary: Exploring the potential of virtual reality to study burglary in action. Journal of Research in Crime and Delinquency, 54(1), 29-62. https://doi.org/10.1177/0022427816663997.

Wright, R., \& Decker, S. H. (1994). Burglars on the job: streetlife and residential break-ins. New Hampshire: UPNE.

Wright, R., Logie, R. H., \& Decker, S. H. (1995). Criminal expertise and offender decision making: an experimental study of the target selection process in residential burglary. Journal of Research in Crime and Delinquency, 32(1), 39-53 doi.org/10.1080/08858190209528804. 
Yaremych, H. E., \& Persky, S. (2019). Tracing physical behavior in virtual reality: a narrative review of applications to social psychology. Journal of Experimental Social Psychology, 85, 103845. https://doi. org/10.1016/j.jesp.2019.103845.

Publisher's note Springer Nature remains neutral with regard to jurisdictional claims in published maps and institutional affiliations.

Iris van Sintemaartensdijk is a PhD candidate at the Department of Experimental and Applied Psychology of the VU University Amsterdam and Psychology of Conflict, Risk and Safety at the University of Twente on the "Virtual Burglary Project." Her research focuses on the role of guardianship and personality in burglar decision-making and the use of virtual reality to study this decision-making process.

Jean-Louis van Gelder is director of the Max Planck Institute for the Study of Crime, Security and Law and Full Professor at the Institute of Education and Child Studies at Leiden University. His research interests include the role of affect and personality in criminal decision making, virtual reality and other technologies to study crime.

Jan Willem van Prooijen is Associate Professor at the Department of Experimental and Applied Psychology of VU University Amsterdam, and Senior Researcher at the Netherlands Institute for the Study of Crime and Law Enforcement (NSCR). His research focuses on unethical behavior, belief in conspiracy theories, and political extremism.

Claire Nee is the director of the International Centre for Research in Forensic Psychology, University of Portsmouth, UK, where she coordinates research on offender cognition, detecting deception, and memory in psycho-legal settings. Her work focuses on cognitive and behavioural aspects of expertise in offenders and methodologies to better understand the offender's insight on their own behaviour.

Marco Otte, MA, spent well over 15 years working in the archaeological industry, where he occupied a number of management positions. Currently, he is in charge of the Tech Labs of the Network Institute at the VU University Amsterdam. He fully participates in academic research as advisor, technical supporter, technical creator, and academic content.

Paul van Lange is Professor at the Department of Experimental and Applied Psychology of VU University Amsterdam, and Institute for Brain and Behavior Amsterdam. His research focuses on the psychology and evolution of trust, conflict and cooperation.

\section{Affiliations}

\section{Iris van Sintemaartensdijk $k^{1,2}$. Jean-Louis van Gelder ${ }^{3,4}$. Jan-Willem van Prooijen ${ }^{1,5} \cdot$ Claire Nee $^{6} \cdot$ Marco Otte $^{7} \cdot$ Paul van Lange $^{1}$}

1 Department of Experimental and Applied Psychology, Vrije Universiteit Amsterdam, Van der Boechorststraat 7, 1081 BT Amsterdam, The Netherlands

2 Department of Psychology of Conflict, Risk and Safety, Universiteit Twente, Enschede, Netherlands

3 Max Planck Institute for the Study of Crime, Security and Law, Freiburg im Breisgau, Germany

4 Institute of Education and Child Studies, Leiden University, Leiden, Netherlands

5 Netherlands Institute for the Study Crime and Law Enforcement, Amsterdam, Netherlands

6 Department of Psychology, University of Portsmouth, Portsmouth, England

7 The Networks Institute, Vrije Universiteit Amsterdam, Amsterdam, Netherlands 